\title{
Educación con raíces ecológicas
}

\author{
Education with Ecological Roots
}

\author{
José Alberto Rubí Barquero? \\ Escuela de Filosofía \\ Universidad Nacional de Costa Rica \\ Heredia, Costa Rica \\ joserubi54@yahoo.com
}

Recibido 28 de octubre de 2011 • Corregido 26 de mayo de 2012 • Aceptado 28 de junio de 2012

Resumen. Este artículo explica cómo la modernidad desarrolla su propia modalidad de de educación para llevar adelante su consigna de conquistar la naturaleza y las consecuencias ambientales de esa concepción. Por lo tanto, se propone una nueva educación que se nutra del saber ecológico y deje atrás la misión fragmentaria y mecanicista del mundo, propia de la modernidad y, en su lugar, alumbre una conciencia alternativa con una nueva manera de relacionarnos con nuestro entorno natural y con nuestros semejantes.

Palabras claves. Modernidad, paradigma, mecanicismo, ecología, educación, contexto.

Abstract. This paper explains how modernity develops its own form of education to achieve its objective of conquering nature, and the related environmental consequences. In this context, this paper proposes a new education nurtured from ecological knowledge, leaving behind the fragmentary and mechanic mission of the world -a characteristic of modernity- to promote an alternative awareness focused on a new way of relationships with our natural environment and other individuals.

Keywords. Modernity, paradigm, mechanistic, ecological, education, context.

\section{Introducción}

La pregunta por las características de la educación del futuro me recuerda, de mis estudios de lógica, la falacia de "pregunta compleja", que se ilustraba con interrogantes como este: ¿ya dejó usted de pegarle a su esposa?, una pregunta que da por un hecho que el interrogado acostumbraba pegarle a su esposa. Del mismo modo, cuando nos preguntan por la educación del mañana, asumen, sin consultarnos previamente por ello, que damos por un hecho que habrá futuro.

Doctor en Educación y Licenciado en Filosofía. Es profesor en la Escuela de Filosofía de la Universidad Nacional de Costa Rica. 
URL: http://www.una.ac.cr/educare

Pero esto de asumir, sin cuestionamiento alguno, que hay futuro, que vendrá inexorablemente como llegan los eclipses o las flores en primavera, es algo que formaba parte del repertorio de creencias de la modernidad y ocupando, en ese repertorio, un lugar central. Es más, esta creencia en la infaltabilidad del futuro tenía un claro trasfondo optimista, dado que formaba parte de otra creencia igualmente moderna, la creencia en el progreso.

Como no es posible en nuestros días actuar como si la modernidad no hubiese entrado en crisis, como si las expectativas que surgieron con el nacimiento de la ciencia moderna se hubiesen logrado y hoy viviésemos en un mundo como el que nos prometía, por ejemplo, Bacon en su libro "La nueva Atlántida", entonces la pregunta por la educación del mañana hay que, por lo menos, matizarla con algunos condicionamientos, donde el más elemental de todos nos lleva a decir, aunque sea para nuestros adentros, "en caso de que haya futuro" .

En efecto, si algo debemos tener claro las personas como yo, nacidas a principios de la segunda mitad del siglo veinte, testigos de lo que tres siglos de industrialismo le han hecho a nuestro planeta, nunca tan cercano como hoy al colapso ecológico, es que nuestro porvenir como especie no es algo que esté garantizado, como sí lo creían las personas que abrazaron, en su momento, la ideología modernista, o dicho con palabras de Dysson (1998, p. 18): "Una lección que aprendemos de la ciencia y de la historia es que el futuro es impredecible".

Ni está garantizado el futuro, ni lo que estamos haciendo como civilización, es decir, con nuestros actuales valores y sus consecuentes estilos de vida, contribuye para nada a garantizarlo. Urge el nacimiento de una nueva conciencia. Nada se gana, como bien lo indicara Einstein, con querer resolver un problema desde el mismo estado de conciencia que lo provocó.

Ciertamente, muchos de los problemas que hoy nos agobian, que nos tienen al borde del colapso como civilización, tienen que ver con el predominio que una visión del mundo y de la vida, fragmentaria y mecanicista, llegó a tener durante el período moderno. Una visión, un paradigma, que pese a su agotamiento, a su caducidad, sigue permeando las conciencias actuales.

Esto explica, por ejemplo, que para los problemas creados por una visión centrada en el crecimiento, se nos ofrezca, como solución, más crecimiento, algo así como pretender aplacar un incendio con la ayuda de un líquido inflamable. Lo mismo podemos observar con los problemas creados por un sistema escolar inoperante y al que se le sigue viendo, sin embargo, como parte de la solución.

Surge, entonces, la siguiente pregunta: ¿Cómo hacemos para que el surgimiento de una nueva conciencia sea parte de un proceso que involucre cada vez más personas; para que los cambios que trae consigo una nueva conciencia trasciendan la esfera individual, los pequeños grupos y lleguen a tener repercusión planetaria? 
Esta pregunta me lleva a tomar en cuenta la educación, pues así como ha servido, hasta el día de hoy, para conformar una conciencia fragmentaria y de inspiración mecanicista, puede servir, de ahora en adelante, para promover el surgimiento de una nueva conciencia, esta vez de carácter integral, holística, alternativa.

En relación con el futuro, esta nueva conciencia está lejos del optimismo que llevaba a los modernos a creer prácticamente en la "bondad natural" de todo cuanto se emprendía en nombre de la ciencia y de la tecnología, en nombre del progreso, y enfatiza que si en verdad queremos contar con un futuro, este futuro hemos de construirlo desde el presente, con cada uno de nuestros actos, solo que esta vez inspirados en un saber integral emanado de una nueva educación de profundas raíces ecológicas.

\section{¿Qué pasa con la educación?}

La escuela, tal y como la conocemos, es un engendro de la era industrial, de ahí que responde, todavía, a los principios del industrialismo. Esos principios son los siguientes:

- Uniformización

- Especialización

- Sincronización

- Concentración

- Maximización

- Centralización

Pero la educación no siempre giró en torno a esas características; anteriores etapas del desarrollo humano, así las llama Philip Snow, citado por Gallegos (1977, pp. 140-141), en su escrito Educación holística y transformación humana, crearon sus propios tipos de educación acordes con las necesidades de sus formas de vida. Según Snow, esas etapas son:

- La era de la humanidad en la naturaleza

- La era de la humanidad con la naturaleza

- La era de la humanidad sobre la naturaleza

- La era de la humanidad a través de la naturaleza 
La era de la humanidad en la naturaleza es la era del cazador recolector; la de la humanidad con la naturaleza es la era de la agricultura; la de la humanidad sobre la naturaleza es la era mecanicista industrial y, la más reciente, la de la humanidad a través de la naturaleza es la era de la información.

De acuerdo con este esquema, el nuestro es, entonces, un tiempo de transición cuyo principal reto es mudar de conciencia, pasar de una conciencia de fragmentación que nos lleva a actuar como si la naturaleza fuese distinta de nosotros, a una conciencia de unidad, donde se sabe que todo está interconectado.

Con el arranque de la era industrial, la de "la humanidad sobre la naturaleza" o en plan de conquista, se llevaron a cabo varias separaciones al interior de realidades que venían funcionando como unidades. Una de ellas fue la separación del productor y el consumidor quien, en la figura del prosumidor (dícese de la persona que produce para su propio consumo) de la era agrícola, eran una sola cosa. Con esta separación cobra fuerza el mercado que se inserta como una cuña entre el productor y el consumidor. Igual le pasa a la familia con muchas de las funciones que tenía a su cargo. Porque la familia de la era agrícola conformada por padres, hijos, abuelos, tíos; todos viviendo bajo un mismo techo, constituía un hogar multifuncional donde se cuidaba a los enfermos, se instruía a los niños, se confeccionaba la ropa y se cultivaban los alimentos, entre otras cosas. Pero, con el auge del industrialismo, esta familia se fue reduciendo y muchas de las funciones que cumplía fueron saliendo de su seno y pasaron a manos de nuevas instituciones con fines específicos, en cuenta la educación de los niños.

Quiere decir que la escuela de la era industrial nace al separar a los niños de su hogar y, en cierta forma, también de su comunidad. No en vano para muchos niños el ingreso a la escuela constituye un desprendimiento doloroso y su estadía en ella nunca llega a ser una experiencia agradable. Una vez en marcha, la escuela irá segregando, día tras día, su propia ideología autojustificadora, hasta el punto de convertirse en el espacio educativo por excelencia, con su sistema de notas y de títulos para decidir acerca de la aptitud e ineptitud de las personas con sentencias irrevocables.

Esta escuela con aspecto de fábrica o, peor aún, con aspecto de cárcel, con celdas por aulas, con maestros autoritarios y represivos, servirá para consolidar, desde su currículo oculto, la visión mecanicista y fragmentaria del mundo y de la vida que el industrialismo trae consigo. La visión que, precisamente, le va a permitir tratar la naturaleza como un depósito inagotable de materias primas para mantener en movimiento, ojalá perpetuo, sus cadenas de ensamblaje y de producción en serie.

En un momento de transición como el que estamos viviendo, este tipo de educación no puede menos que estorbar al alumbramiento de la nueva conciencia, necesaria para promover los cambios que la situación actual reclama. 
REVISTA ELECTRÓNICA EDUCARE

URL: http://www.una.ac.cr/educare

\section{¿Es imprescindible la escuela?}

"La educación es admirable, pero nada que valga la pena saberse puede ser enseñado"

Oscar Wilde

"Suspendí mi educación cuando tuve que ir al colegio"

Bernard Shaw

De cara a la escuela como frente a cualquier realidad consumada cabe el asombro, es decir, la actitud que reconoce que las cosas son como son; pero que, al mismo tiempo, se pregunta si necesariamente tienen que ser así. La escuela es, en efecto, el lugar deliberadamente creado para que ahí se lleve a cabo la educación, pero esto no debe impedir que uno pueda preguntarse si ese mismo cometido no se podrá lograr sin la escuela o fuera de la escuela. Sobre todo, cuando es evidente que la escuela, con su particular separación del resto de la sociedad, con su forma fragmentada de asumir el conocimiento, está más del lado del problema que del lado de la solución.

Si de todos modos se le quisiera mantener a la escuela cierto rol educativo que no sea, claro está, el de abortar, como todo parece indicar que lo hace ahora, la gestación de una nueva conciencia, la escuela tendría que experimentar cambios cualitativos importantes, comenzando por un derribamiento, aunque sea simbólico, de sus paredes; esas paredes de todo tipo que la mantienen olímpicamente incomunicada con la realidad a la cual se debe. Lejos de un centro de reclusión, la escuela debe ser un lugar de convergencia de los diferentes actores sociales para lo cual necesita abrirse, entrar en un contacto multidimensional con su comunidad en un proceso de doble vía: desde el interior de la escuela hacia la comunidad y desde la comunidad hacia la escuela en un todo indivisible. Así, la comunidad toda sería una escuela y la escuela una comunidad.

Este cambio debe ir acompañado de otro igualmente importante que tiene que ver con la actual concepción del conocimiento, una concepción que procede a dividir el todo que se quiere conocer en cada una de sus partes, como recomienda Descartes en la segunda regla de su método; pero que, en ese dividir y en ese repartirse entre las distintas ciencias los aspectos que cada una considera de su interés, el todo, como tal, queda en el olvido. Aquí, el entusiasmo por el análisis opaca la importancia de la síntesis. Y la escuela no puede 
URL: http://www.una.ac.cr/educare

seguir por este camino de quedarle debiendo al aprendiente la visión global, holística, del mundo y de la vida; según Damián (1997) "(...) la visión holística, que se fundamenta en el principio de interconexión de todas las cosas y la necesidad de una conciencia planetaria" (p. 11). La nueva educación sabe que educar es educar holísticamente, que buena parte de lo malo que hoy nos pasa como civilización proviene de esa visión fragmentada que la era industrial consideró conveniente promover desde las aulas para que funcionara en las fábricas.

Señala Ramón Gallegos:

La educación holista, es el tipo de educación que necesitamos para poder enfrentar correctamente los dilemas del siglo XXI. En esta educación se percibe al estudiante de una manera diferente. La escuela deja de ser una fábrica para convertirse en un sistema vivo. El aprendizaje es inherente a todo lo que hacemos. Todos en la escuela son tanto maestros como alumnos. La comunidad local y global es finalmente el aula de clase y se percibe el aprendizaje como algo implícito a toda experiencia humana. (Gallegos, 1977, p. 194)

\section{La nueva educación}

"No es la escuela la que nos enseña sino la vida"

Séneca

Los modernos inscribieron su educación dentro de una visión del mundo y de la vida de inspiración mecanicista. Esta la hicieron posible, entre otros, Galileo, Newton y Descartes. No ha de extrañarnos, entonces, que principios de la física fueran convertidos en principios pedagógicos tal y como lo muestra la película "Los chicos del coro", donde uno de los maestros asume que los chicos se comportan de acuerdo con el principio de acción y reacción igual que lo hacen las bolas de billar.

Esta visión mecanicista tuvo que dar su lucha para desplazar a visiones más antiguas como las que encontramos en los mitos -antropomórficas unas, animistas otras- hasta convertirse en la visión dominante de occidente. Con su consolidación, el mundo de lo vivo se empobreció notablemente; mucho de lo que se creía que tenía vida, alma, espíritu y que, por lo tanto, se cuidaba y se respetaba, fue rebajado a la categoría de simple materia disponible para echar a andar la nueva producción capitalista. 
El triunfo del mecanicismo significa la desacralización de la naturaleza. A partir de ahí, ya no hay nada que le impida a las nuevas fuerzas productivas disponer a su antojo de cuanto se les ponga por delante: bosques, manglares, pantanos, cerros, lagos, lo que sea, después de todo, lo que hagan será para doblegar la naturaleza y ponerla "al servicio del hombre" y a eso se le denomina progreso, es decir, el nuevo dios de la religión modernista. En palabras de Sheldrake (1994):

(...) a través de la revolución mecanicista, el antiguo modelo del cosmos viviente fue reemplazado por la idea del universo como máquina. Según esta nueva teoría del mundo, la naturaleza ya no tenía una vida propia: carecía de alma, de espontaneidad, libertad y creatividad. La Madre Naturaleza no era más que materia muerta que se movía en obediencia perfecta a las leyes matemáticas establecidas por Dios. (p. 61)

Si no fuera porque con este trato el planeta ha comenzado a dar señales inequívocas de que su salud está seriamente amenazada -señales que han servido para que caigamos en la cuenta de que no se trata de una gran máquina a la que se le pueden cambiar las piezas dañadas para que vuelva a funcionar, sino de un ser vivo, un asombroso organismo cuya vida es posible gracias al mantenimiento de ciertos equilibrios-, posiblemente el credo modernista con sus loas al progreso seguiría reinando como en los mejores días del siglo XIX.

No quisiera continuar sin reconocer que aún con todas esas señales -el calentamiento global, huecos en la capa de ozono, desertificación acelerada, etc.- todavía hay muchos que siguen creyendo en soluciones tecnológicas, sin ver que se trata de problemas originados en nuestra manera de relacionarnos con el medio y que, en esa manera de relacionarnos, intervienen valores. Es decir, en el fondo se trata de un asunto ético que pide cambios al interior de nosotros mismos. Desde esta perspectiva, "soluciones" tan publicitadas como los carros eléctricos porque "no contaminan" no pasan de ser "más de lo mismo", solo sirven para recordarnos lo atinado de la advertencia de Einstein citada más arriba.

Con lo dicho hasta aquí queda claro que la nueva educación ha de ahondar sus raíces en el nuevo saber ecológico, nutriéndose de aportes como los de-Lovelock (2000) recogidos en su libro "Las edades de Gaia", donde se demuestra que nuestro planeta es un ser vivo y que no tiene sentido compararlo con una máquina.

Pero este necesario abrirse de la educación ante el saber ecológico no debe quedarse solo en asuntos de contenido; la educación que nuestro tiempo demanda debe ecologizarse en el sentido más amplio posible del término, de tal forma que se vea influenciada hasta en sus aspectos formales. Que esto último es posible lo pone de manifiesto Morin (2002), en su libro $L a$ cabeza bien puesta, cuando dice: 
URL: http://www.una.ac.cr/educare

El desarrollo de la aptitud para contextualizar tiende a producir el surgimiento de un pensamiento "ecologizante" en el sentido de que sitúa todo acontecimiento, información o conocimiento en una relación inseparable con el medio -cultural, social, económico, político y, por supuesto, natural-. No hace más que situar un acontecimiento en su contexto, incita ver cómo éste modifica al contexto o cómo le da una luz diferente. Un pensamiento de este tipo se vuelve inseparable del pensamiento de lo complejo, pues no basta con inscribir todas las cosas y hechos en un "marco" u "horizonte". Se trata de buscar siempre las relaciones e interretro-acciones entre todo fenómeno y su contexto, las relaciones recíprocas entre el todo y las partes: cómo una modificación local repercute sobre el todo y cómo una modificación del todo repercute sobre las partes. Al mismo tiempo, se trata de reconocer la unidad dentro de lo diverso, lo diverso dentro de la unidad, reconocer, por ejemplo, la unidad humana a través de las diversidades individuales y culturales, las diversidades individuales y culturales a través de la unidad humana. Finalmente, un pensamiento que vincule se abre hacia el contexto de los Contextos, el contexto planetario. (p. 27)

El saber ecológico, ciertamente, es un saber ejercitado para ver a los seres vivos en su contexto, formando una unidad inseparable. Ya en el aula, este pensamiento "ecologizante" debe inspirar un principio pedagógico, según el cual explicar es contextualizar, mostrar o sugerir las relaciones que guardan las distintas cosas entre sí. Mi experiencia como aprendiente me confirma lo interesante que resulta poder ver las cosas - un hecho histórico, una obra de arte, una creencia religiosa, etc.- en relación con su contexto, dado que el contexto ayuda a entender y entender produce gozo.

\section{Conclusión}

Si la educación a través de la escuela quiere jugar un papel educativo relevante en este momento crucial, ha de convertirse en partera, como la entendía Sócrates cuando dialogaba con los jóvenes en las calles de Atenas, y contribuir decididamente en el alumbramiento de una nueva conciencia, esa que se enriquece diariamente con lo mejor del saber ecológico, el mismo que nos dice algo que nuestros antepasados sabían y que nosotros no pudimos heredar de ellos, por eso de que, en algún momento, nos creímos más sabios: 
"Esto sabemos,

Todo está conectado

como la sangre

que une a una familia ...

Lo que le acaece a la tierra

acaece a los hijos e hijas de la tierra.

El hombre no tejió la trama de la vida;

es una mera hebra de la misma.

Lo que le haga a la trama,

se lo hace a sí mismo."

Ted Perry (1970) (inspirado en el Jefe Seattle)

\section{Referencias}

Bacon, F. (2006). La nueva Atlántida. Madrid: Ediciones AKAL.

Damián, V. (1997). Educación holista para una conciencia planetaria. En R. Gallegos (Comp.), EI destino indivisible de la Educación. Propuesta holística para redefinir el diálogo humanidadnaturaleza en la enseñana (pp. 9-32). México: Pax.

Dyson, F. (1998). Mundos del futuro. Barcelona: Grijalbo.

Gallegos, R. (Comp.). (1997). El destino indivisible de la Educación. Propuesta holística para redefinir el diálogo humanidad-naturaleza en la enseñanza. México: Pax.

Lovelock, J. (2000). Las edades de Gaia. Una biografía de nuestro planeta vivo (3a. ed.). Barcelona: Tusquets Editores.

Morin, E. (2002). La cabeza bien puesta: Repensar la reforma. Reformar el pensamiento. Buenos Aires, Argentina: Ediciones Nueva Visión. Recuperado de http://es.scribd.com/doc/43009388/ Morin-1999-La-Cabeza-Bien-Puesta

Perry, T. (1970). Home, [Guión de película para serie de televisión] En J. Stevens (Productor). Comisión de Radio y Televisión de los Bautistas del Sur.

Sheldrake, R. (1994). El renacimiento de la naturaleza. La nueva imagen de la ciencia y de Dios. España: Paidos.

Snow, P. (1997). Educación holística y transformación humana. En R. Gallegos Nava, (Comp.). El destino indivisible de la Educación. Propuesta holística para redefinir el diálogo humanidadnaturaleza en la enseñana (pp. 140-141). Pax: México. 